\title{
Endoscopic Biliary Irrigation with N-Acetylcysteine of Intraductal Papillary Mucinous Neoplasm of Bile Ducts
}

\section{Yen-Chun Peng ${ }^{1,2}$ and Wai-Keung Chow ${ }^{3^{*}}$}

${ }^{1}$ Division of gastroenterology, Taichung Veterans General Hospital, Taichung, Taiwan

${ }^{2}$ School of Medicine, National Yang-Ming University, Taipei, Taiwan

${ }^{3}$ Divsion of Gastroeneterolgy, Taichung Tzu-Chi Hospital, Taichung, Taiwan

\begin{abstract}
Sixty-six year old man came to our hospital due to abnormal liver function test since May 2014. After serial image study, he was diagnosed as intraductal papillary mucious neoplasm of biliary tract by magnetic resonance cholangiopancreatography (ERCP) and computed tomography (Figure 1a,1b,1c). He has dilated biliary tract fulfilled with mucin production. Jaundice is also determined due to mucin obstructed biliary tract. He wants to receive nonsurgical treatment for his mucin producing biliary neoplasm.
\end{abstract}

\section{Publication History:}

Received: October 26, 2017

Accepted: December 28, 2017

Published: December 30, 2017

\section{Keywords:}

Bile ducts, Endoscopy, Fluoroscopy image, N-Acetylcysteine

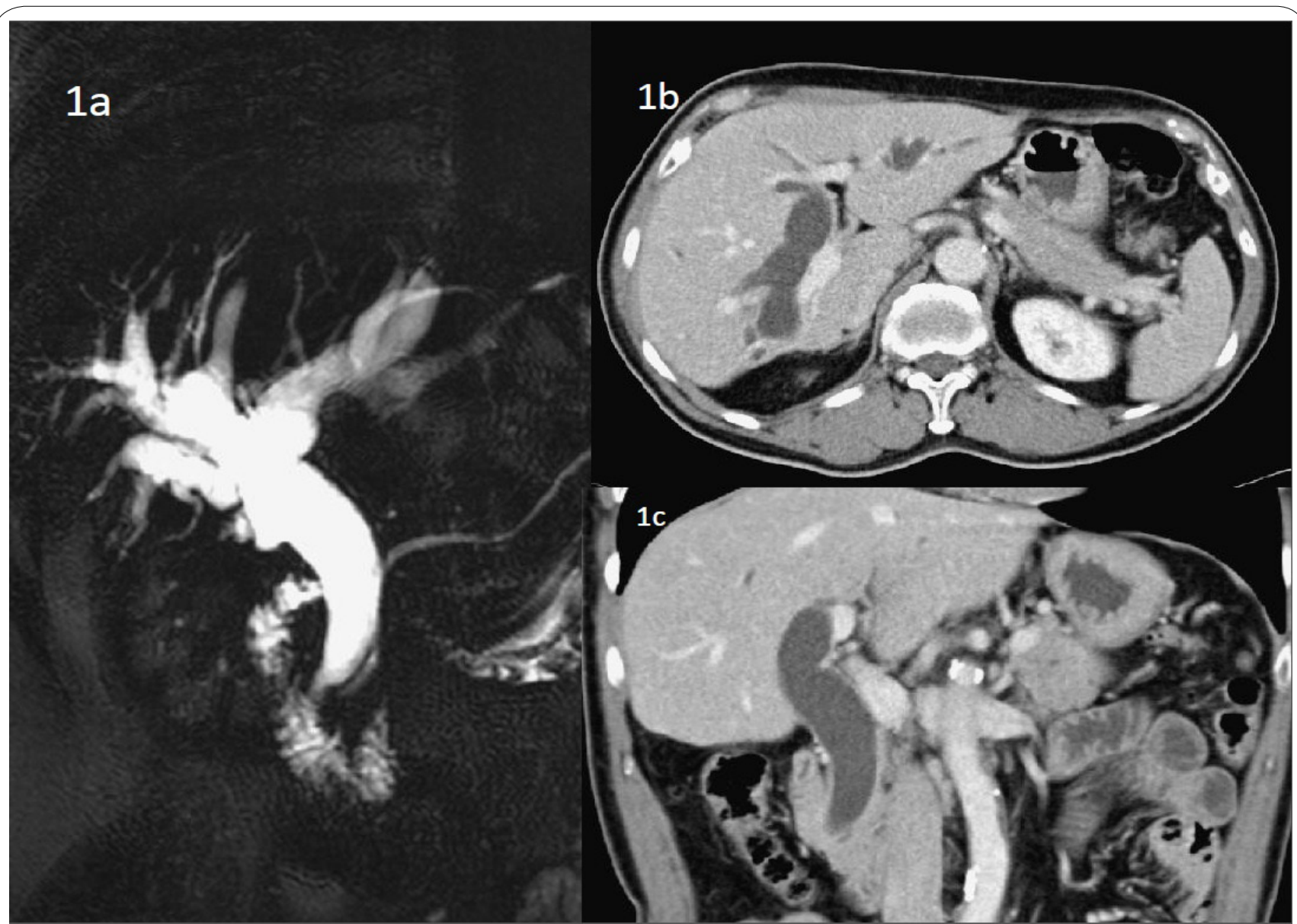

Figure 1: Intraductal papillary mucious neoplasm of biliary tract by magnetic resonance cholangiopancreatography (ERCP) and computed tomography.

Percutaneous tranhepatic cholangial drainage (PTCD) was performed for biliary drainage. Besides, mucin cleaning by endoscopic retrograde cholangiogram (ERCP) with basket extraction was also performed periodically. However, due to the sticky of mucin, there are some difficulties in cleaning of biliary mucin by tradition basket in the previous serial ERCP with basket or balloon extraction. The fluoroscopy image showed mucin related poor biliary image to figure the biliary tract (Figure 2a, 2b).

Recently, we used N-Acetylcysteine, which is a mucolytic agent, mixed with normal saline $(600 \mathrm{mg}$ in $200 \mathrm{cc}$ ), and mixed with contrast
"Corresponding Author: Dr. Wai-Keung Chow, Division of Gastroenterology, Taichung Tzu-Chi Hospital, No 66, Sec 1, Fong-Hsin Rd. Taichung, Taiwan; E-mail: wkchow2010@gamil.com

Citation: Chow WK, Peng YC (2017)Endoscopic Biliary Irrigation with N-Acetylcysteine of Intraductal Papillary Mucinous Neoplasm of Bile Ducts. Int J Gastroenterol Disord Ther 4: 135. doi: https://doi.org/10.15344/2393$8498 / 2017 / 135$

Copyright: $\odot 2017$ Chow et al. This is an open-access article distributed under the terms of the Creative Commons Attribution License, which permits unrestricted use, distribution, and reproduction in any medium, provided the original author and source are credited. 
Citation: Chow WK, Peng YC (2017)Endoscopic Biliary Irrigation with N-Acetylcysteine of Intraductal Papillary Mucinous Neoplasm of Bile Ducts. Int J Gastroenterol Disord Ther 2: 134. doi: http://dx.doi.org/10.15344/2393-8498/2017/134

Page 2 of 3

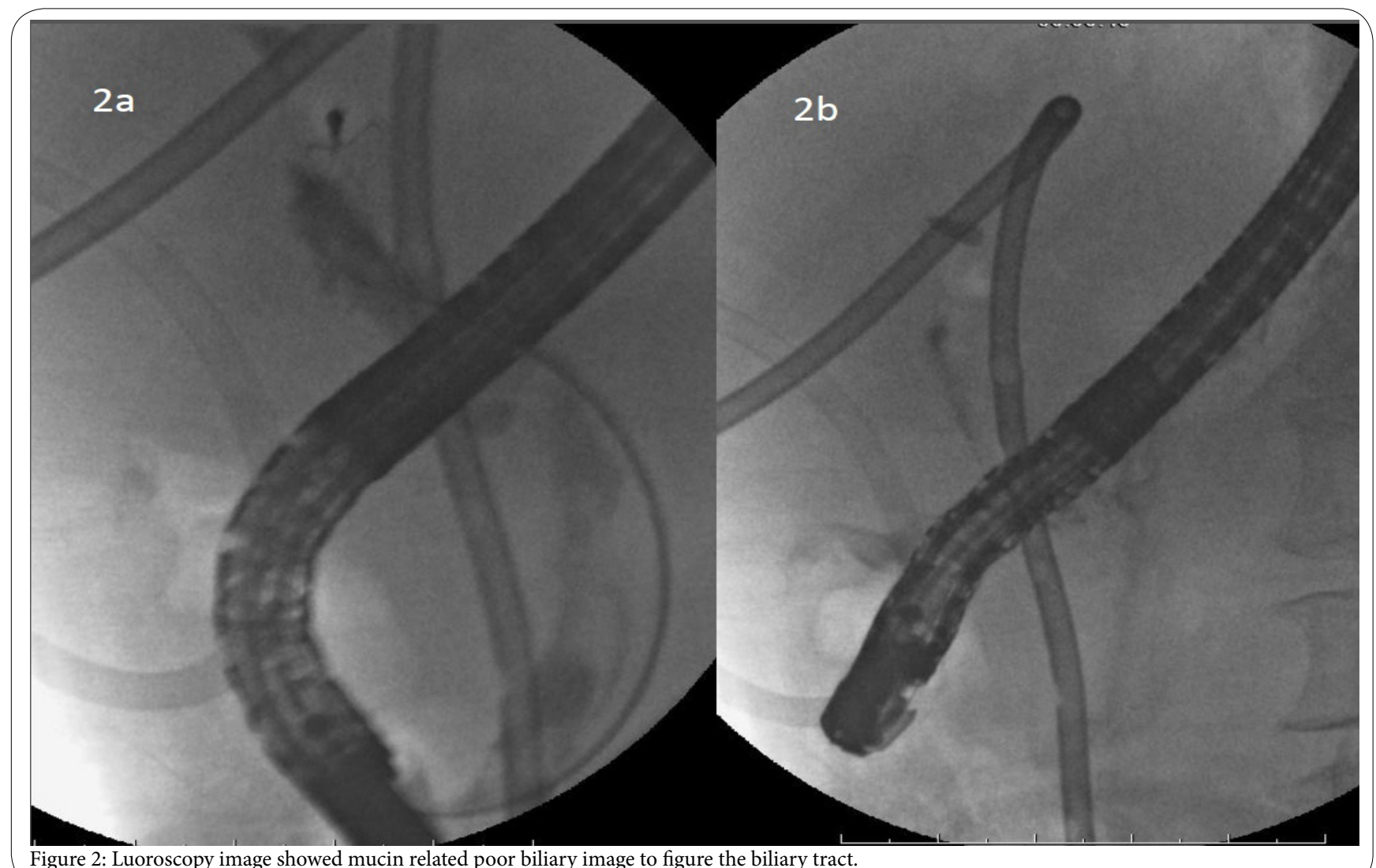

Figure 2: Luoroscopy image showed mucin related poor biliary image to figure the biliary tract.

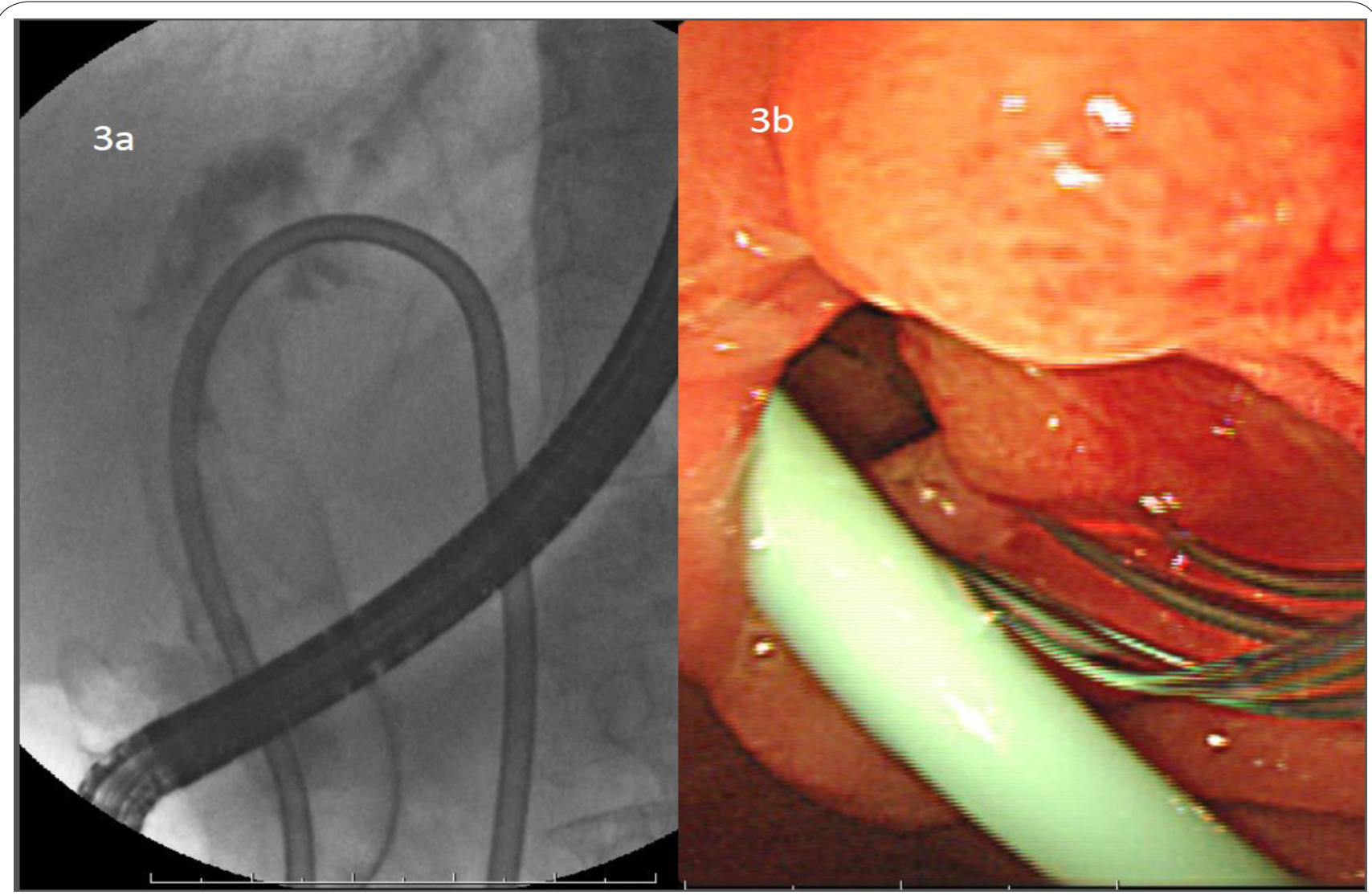

Figure 3: (a) N-Acetylcysteine mixed with normal saline (b) endoscopy of the impacted mucin of common bile duct orifice. 
Citation: Chow WK, Peng YC (2017)Endoscopic Biliary Irrigation with N-Acetylcysteine of Intraductal Papillary Mucinous Neoplasm of Bile Ducts. Int J Gastroenterol Disord Ther 2: 134. doi: http://dx.doi.org/10.15344/2393-8498/2017/134

Page 2 of 3

medium to irrigation of biliary mucin during ERCP. We could find that it decreased the viscosity of biliary mucin by basket extract and the endoscopic suctioning of mucin was also smooth. By image, the fluoroscopy could demonstrate a clear figure of biliary tract (figure 3a). By endoscopy, the impacted mucin of common bile duct orifice was also suctioned out completely (Figure 3b).

$\mathrm{N}$-Acetylcysteine that decreases the viscosity of mucus, and is used for respiratory tract [1]. Additionally, it is a protected and mucolytic drug that could mellow tenacious mucous discharges or secretions. It is reported to be used for biliary mucin through nasobiliary catheter and PTCD for improving of symptoms [2,3]. Our presentation demonstrated that normal saline mixed $\mathrm{N}$-Acetylcysteine is also feasible in basket extract and suction by ERCP procedure.

\section{Competing Interests}

The authors declare that they have no competing interests.

\section{References}

1. Mokhtari V, Afsharian P, Shahhoseini M, Kalantar SM, Moini A, et al. (2017) A Review on Various Uses of N-Acetyl Cysteine. Cell Journal (Yakhteh) 19: 11-17.

2. Hong MY, Yu DW, Hong SG (2014) Intraductal papillary mucinous neoplasm of the bile duct with gastric and duodenal fistulas. World J Gastrointest Endosc 6: 328-333

3. $\mathrm{Hu} \mathrm{LH}$, Liu MH, Liao Z, Zou WB, Ye B, et al. (2012) Continuous infusion of $\mathrm{N}$-acetylcysteine by nasobiliary for advanced intraductal papillary mucinous neoplasm of bile ducts (with video). Am J Gastroenterol 107: 1929-1930. 